\title{
T7 peptide cytotoxicity in human hepatocellular carcinoma cells is mediated by suppression of autophagy
}

\author{
FENG LIU $^{1}$, FUHAI WANG $^{1}$, XIAOFENG DONG ${ }^{2}$, PENG XIU $^{1}$, PENGFEI SUN ${ }^{3}$, \\ ZHONGCHAO $\mathrm{LI}^{3}$, XUETAO $\mathrm{SHI}^{3}$ and JINGTAO ZHONG ${ }^{3}$ \\ ${ }^{1}$ Department of General Surgery, Qianfoshan Hospital, Shandong University, Jinan, Shandong 250014; \\ ${ }^{2}$ Department of Hepatobiliary Surgery, The People's Hospital of Guangxi Zhuang Autonomous Region, Nanning, \\ Guangxi 530021; ${ }^{3}$ Department of Hepatobiliary Surgery, Shandong Cancer Hospital Affiliated to Shandong University, \\ Shandong Academy of Medical Science, Jinan, Shandong 250117, P.R. China
}

Received December 23, 2018; Accepted June 4, 2019

DOI: 10.3892/ijmm.2019.4231

\begin{abstract}
The T7 peptide, an active fragment of full-length tumstatin [the non-collagenous 1 domain of the type IV collagen $\alpha 3$ chain, $\alpha 3$ (IV) NC1], has exhibited potential antitumor effects in several types of cancer cells. However, the mechanism underlying its action against human hepatocellular carcinoma (HCC) remains unclear. The present study aimed to investigate the role of autophagy in T7 peptide-induced cytotoxicity in HCC cells in vitro and in vivo. The results revealed that the $\mathrm{T} 7$ peptide significantly reduced cell viability and induced cell cycle arrest in HCC cells. The T7 peptide induced apoptosis in HCC cells through upregulation of Bax, Fas, and Fas ligand, and through upregulation of the anti-apoptotic protein Bcl-2. In addition, treatment with the $\mathrm{T} 7$ peptide induced protective autophagy in HCC cells. Blocking autophagy by 3-methyladenineor bafilomycin A1 enhanced T7 peptide-induced apoptosis. Furthermore, co-treatment with MK-2206 (an Akt specific inhibitor) or rapamycin (an inhibitor of mTOR) enhanced T7 peptide-induced autophagy, whereas co-treatment with insulin (an activator of the Akt/mTOR signaling pathway) alleviated T7 peptide-induced autophagy, which suggested that the T7 peptide may induce autophagy activation via inhibition of the Akt/mTOR signaling pathway. Taken together, the present results demonstrated that suppression of autophagy potentiated the cytotoxic effects of the T7 peptide, and suggested that the T7 peptide may serve as a potential alternative compound for HCC therapy.
\end{abstract}

Correspondence to: Dr Jingtao Zhong, Department of Hepatobiliary Surgery, Shandong Cancer Hospital Affiliated to Shandong University, Shandong Academy of Medical Science, 440 Jiyan Road, Jinan, Shandong 250117, P.R. China

E-mail: jingtao2005@126.com

Key words: hepatocellular carcinoma, T7 peptide, tumstatin, autophagy, apoptosis, Akt, mTOR

\section{Introduction}

Hepatocellular carcinoma (HCC) ranks sixth among the common types of cancer worldwide and is the third leading cause of cancer-related mortality (1). The main risk factors of HCC are cirrhosis from hepatitis virus infection (hepatitis B or $\mathrm{C}$ viruses), alcohol-related liver cirrhosis, and non-alcoholic steatohepatitis (2). In the past decades, therapeutic options for HCC have considerably developed, including radiofrequency ablation, liver transplantation, tumor resection, transarterial chemoembolization, and chemotherapy. However, they do not always have a favorable safety and efficacy ratio. The 5-year survival rate for patients with HCC remains low (3). Therefore, novel therapeutic strategies are urgently needed.

Tumstatin is an endogenous angiogenesis inhibitor that is derived from the non-collagenous 1 domain fragment of the type IV collagen $\alpha 3$ chain [ $\alpha 3(\mathrm{IV}) \mathrm{NC} 1]$, a basement membrane collagen which binds to integrin $\alpha v \beta 3$ and $\alpha 3 \beta 1$ (4). Tumstatin has 244 amino acids and its gene has $738 \mathrm{bp}$. The molecular weight of tumstatin is $28 \mathrm{kDa}$ (5). Previous studies demonstrated that tumstatin can suppress cell growth, invasion and angiogenesis, and promote apoptosis in many cancer cells (6-8). However, several studies have revealed that tumstatin is a pathogenic antigen with a high molecular weight, which may cause glomerulonephritis and lung hemorrhage (9). The T7 peptide, which comprises amino acids 74-98 of the collagen IV $\alpha 3$ chain, is a fragment that contains the entire anti-angiogenic activity associated with tumstatin (10). The lower molecular weight of this fragment reduces its immunogenicity and improves the safety of tumstatin (11). Our previous study revealed that the T7 peptide suppresses angiogenesis and exhibits antitumor effects via inhibition of angiopoietin 2 (Ang2), matrix metalloproteinase-2 (MMP-2) and the AKT pathway in human umbilical vein endothelial cells (HUVECs) (12). In addition, the T7 peptide induces autophagy and inhibition of autophagy potentiates the anti-angiogenic activity of the T7 peptide (12).

Autophagy is a highly regulated and fundamental cellular homeostatic process, in which cytoplasmic proteins and organelles are sequestered within double-membrane structures and are delivered to lysosomes for degradation (13). Autophagy 
is activated in response to various forms of cellular stress, including starvation, hypoxia, and radiation. Some anticancer drugs have also been reported to induce autophagy and apoptosis $(14,15)$. However, the role of autophagy in HCC remains unclear. A previous study has reported that autophagy inhibitors could exert tumor-suppressive effects in an HCC rat model in the tumor-forming stage while having a tumor-promoting effect in the dysplastic stage, which suggests that the actual functions of autophagy in the occurrence and development of HCC may be dependent on the context of liver cells (16). Our previous data revealed that inhibition of autophagy can enhance the anti-angiogenic activity of the T7 peptide in HUVECs and enhance meloxicam lethality to HCC cells, which indicates that targeting autophagy to sensitize cancers may be an effective therapeutic strategy to overcome drug resistance $(12,17)$. Therefore, the present study was designed to further explore the effects of T7 peptide in HCC and autophagy.

\section{Materials and methods}

Cell culture and animals. Human HCC cells, Huh-7 and Hep3B, were obtained from the American Type Culture Collection. The normal human liver cell lines, L-02, were purchased from the BeNa Culture Collection. The cells were cultured in Dulbecco's modified Eagle's medium (DMEM; HyClone; GE Healthcare Life Sciences) containing 10\% fetal bovine serum (FBS; Gibco; Thermo Fisher Scientific, Inc.), $100 \mathrm{U} / \mathrm{ml}$ penicillin, and $100 \mu \mathrm{g} / \mathrm{ml}$ streptomycin (Gibco; Thermo Fisher Scientific, Inc.) at $37^{\circ} \mathrm{C}$ in $95 \%$ air and $5 \% \mathrm{CO}_{2}$.

A total of 21 healthy BALB/c male athymic mice (age, 5-6 weeks; weight, 18-22 g) were obtained from the Beijing Vital River Laboratory Animal Technology Co., Ltd. The mice were maintained in polypropylene cages $(n=7$ per cage) in an air-conditioned room $\left(25 \pm 1^{\circ} \mathrm{C}\right.$, relative humidity $50 \pm 20 \%$, 12-h light/dark cycle). All experimental procedures related to animals were approved by the Committee of Animal Experimentation and the Ethics Committee of Qianfoshan Hospital, Shandong University.

Reagents and antibodies. The recombinant $\mathrm{T} 7$ peptide was purchased from Shanghai Bootech Bioscience and Technology Co., Ltd. and dissolved in $30 \%$ acetic acid. 3-methyladenine (3-MA), rapamycin, and insulin were purchased from Sigma-Aldrich (Merck KGaA). MK-2206 was obtained from Merck KGaA. Antibodies against Bax (cat. no. 2772), Bcl-2 (cat. no. 2872), AKT (cat. no. 9272), phosphorylated (p-) AKT (Ser473; cat. no. 9271), mTOR (cat. no. 2972), p-mTOR (Ser2448; cat. no. 2971). and autophagy-related 5 (Atg5; cat. no. 2630) were purchased from Cell Signaling Technology, Inc. Antibodies against Fas (cat. no. ab82419), Fas ligand (Fas-L; cat. no. ab15285), Beclin-1 (cat. no. ab62557), microtubule associated protein 1 light chain $3 \beta$ (LC3B; cat. no. ab51520) and GAPDH (cat. no. ab37168) were obtained from Abcam.

Cell viability assay. Cell viability assays were performed by using the Cell Counting Kit-8 (CCK-8; Dojindo Molecular Technologies, Inc.). Cells $\left(5 \times 10^{3} /\right.$ well) were seeded with culture medium onto 96 -well plates and incubated at $37^{\circ} \mathrm{C}$. After adaptation, cells were treated with various concentrations of the
T7 peptide $(0.25,0.5,1$ and $2 \mu \mathrm{M})$. Then the culture medium was replaced with fresh medium containing $10 \mu \mathrm{l}$ of CCK-8 solution. The optical density (OD) at $450 \mathrm{~nm}$ was assayed following cell incubation at $37^{\circ} \mathrm{C}$ for $2 \mathrm{~h}$. The viability inhibition rate was calculated as: (control OD value-experiment OD value)/control group OD value $\mathrm{x} 100 \%$.

Cell apoptosis assay. Cells were stained with the Annexin V-FITC apoptosis detection kit (BD Biosciences). According to the manufacturer's instructions, the cells were incubated with $5 \mu \mathrm{l}$ of Annexin $\mathrm{V}$ and $5 \mu \mathrm{l}$ of propidium iodide (PI) for $15 \mathrm{~min}$ at room temperature, and then the stained cells were analyzed on a flow cytometer using the FACSDiva software v8.0.1 (BD Biosciences).

Cell cycle assay. HCC cells were treated with the T7 peptide for $24 \mathrm{~h}$ and then the cells underwent cell cycle analysis. In brief, $5 \times 10^{4}$ cells were suspended in $0.5 \mathrm{ml}$ of PI solution, and incubated for $30 \mathrm{~min}$ in the dark, according to the manufacturer's instructions (BD Biosciences). The cell cycle distribution was analyzed by flow cytometry.

Western blot analysis. Huh-7 and Hep3B cells were treated with $1 \mu \mathrm{M}$ of T7 peptide, $5 \mu \mathrm{M}$ MK-2206 or $100 \mathrm{nM}$ rapamycin for $24 \mathrm{~h}$. In other experiments, HCC cells were treated with $1 \mu \mathrm{M}$ T7 peptide for $24 \mathrm{~h}$, followed by treatment with or without $200 \mathrm{nM}$ insulin for $30 \mathrm{~min}$. After the indicated treatments, the cells were harvested and lysed in cold radioimmunoprecipitation assay lysis buffer (cat. no. P0013B; Beyotime Institute of Biotechnology) with $1 \mathrm{nM}$ phenylmethylsufonyl fluoride (PMSF), followed by centrifugation at $12,000 \times \mathrm{g}$ at $4^{\circ} \mathrm{C}$ for $10 \mathrm{~min}$. To prepare protein extracts from tissues, $\sim 30 \mathrm{mg}$ fresh tumor tissue was ground and placed on ice. This was followed by the addition of $300 \mu 1$ ice-cold lysis buffer and $2 \mu \mathrm{l}$ PMSF. The samples were then centrifuged at $12,000 \mathrm{x} \mathrm{g}$ at $4^{\circ} \mathrm{C}$ for $15 \mathrm{~min}$. The protein concentrations in were determined using a bicinchoninic acid assay (Bio-Rad Laboratories, Inc.). Total proteins (20-40 $\mu \mathrm{g})$ were separated using SDS-PAGE (8-12\% gel) and electrotransferred to polyvinylidene fluoride membranes (EMD Millipore). The membranes were blocked with 5\% skim milk in Tris-buffered saline containing $0.05 \%$ Tween-20 for $2 \mathrm{~h}$ at room temperature, and incubated with primary antibodies overnight at $4^{\circ} \mathrm{C}(1: 1,000$ for Bax, Bcl-2, AKT, p-AKT, mTOR, p-mTOR, Atg5, Fas, Fas-L, Beclin-1 and GAPDH; 1:3,000 for LC3B). Membranes were then incubated with horseradish peroxidase-conjugated secondary antibodies (cat. no. 7074; 1:2,000; Cell Signaling Technology, Inc.) for $1 \mathrm{~h}$ at room temperature followed by visualization with enhanced chemiluminescence immunoblotting detection reagents (EMD Millipore). Protein band intensities were quantified by densitometric analysis using ImageJ software (National Institutes of Health).

Immunofluorescence assay. Huh-7 and Hep3B cells were seeded onto cover-slips in 6-well plates, fixed with $4 \%$ paraformaldehyde (PFA) for $20 \mathrm{~min}$, and permeabilized with $0.1 \%$ Triton $\mathrm{X}-100$ for $10 \mathrm{~min}$ at room temperature. The samples were blocked with PBS containing $2 \%$ bovine serum albumin (Sigma-Aldrich; Merck KGaA) for $1 \mathrm{~h}$ at room temperature and further incubated with primary antibodies 
(LC3B, cat. no. ab51520; 1:2,000; Abcam) overnight at $4^{\circ} \mathrm{C}$. The following day, the samples were incubated with secondary antibodies (cat. no. ab150077; 1:1,000; Abcam) for $2 \mathrm{~h}$ at room temperature in the dark and then cells were mounted onto microscope slides with a DAPI mounting solution (Abcam). Images of the HCC cells were captured and analyzed with a fluorescent microscope (magnification, x200; Olympus Corporation).

TUNEL assay. Apoptosis was analyzed using the ApopTag Peroxidase in situ Apoptosis Detection kit (EMD Millipore). The tumor tissues were fixed in $4 \%$ paraformaldehyde at $4^{\circ} \mathrm{C}$ for $24 \mathrm{~h}$, paraffin-embedded and sectioned (thickness, $3 \mu \mathrm{m})$. Tissue sections were deparaffinized and rehydrated and then incubated for 15-30 min at room temperature with $20 \mu \mathrm{g} / \mathrm{ml}$ proteinase $\mathrm{K}$ working solution (Beyotime Institute of Biotechnology). Subsequently, the TUNEL reaction mixture was added to the tumor sections. Following incubation in a humidified container for $2 \mathrm{~h}$, the sections were mounted using anti-fluorescence quenching agent (Beyotime Institute of Biotechnology) and five random fields per slide were observed under a fluorescent microscope (magnification, x200; Olympus Corporation).

Measurement of in vivo activity. Hep3B cells $\left(5 \times 10^{6}\right.$ in $0.1 \mathrm{ml}$ PBS) were subcutaneously injected into the armpit of nude mice. The mice were observed until tumors reached a volume of $100 \mathrm{~mm}^{3}$. Then, the mice were randomized into three groups (7 in each group) and marked. The two experimental groups were administered an intraperitoneal injection of $\mathrm{T} 7$ peptide (dissolved with $0.9 \%$ normal saline) at doses of $2.5 \mathrm{mg} / \mathrm{kg}$ (dose/mouse body weight) or $5 \mathrm{mg} / \mathrm{kg}$ every other day. The control group was treated with the same volume of $0.9 \%$ normal saline. Mouse weight and tumor volume were recorded every second day until the animals were sacrificed. The tumor volume (V) was monitored by measuring its length (L) and width (W) with calipers and calculated by using the following formula: $\mathrm{V}=\left(\mathrm{LxW}^{2}\right) \times 0.5$. The longest diameter exhibited by a single subcutaneous tumor in this study was $1.5 \mathrm{~cm}$. The tumor growth ratio was calculated as follows: the volume of tumor (n day)/the first measured volume of tumor (on day 5; where $n=5,10,15,20,25,30$ and 35). The first-time measured volume of tumor on the fifth day was defined as 1 unit. The mice were sacrificed 5 weeks after the tumor cell inoculation.

Statistical analysis. Data were analyzed with SPSS software (version 17.0; SPSS, Inc.) and expressed as the mean \pm standard deviation. Student's t-tests were used for comparisons between two groups, and one-way analysis of variance followed by Tukey's post hoc test was applied to compare differences between multiple groups. $\mathrm{P}<0.05$ was considered to indicate a statistically significant difference.

\section{Results}

Treatment with the $T 7$ peptide reduces cell viability in human HCC cells. Fig. 1A presents a schematic of the T7 peptide. In our previous study, it was demonstrated that the T7 peptide can significantly inhibit cell growth of HUVECs (12). The current study explored the effect of the T7 peptide on the cell viability of HCC cells in vitro. $\mathrm{HCC}$ cells were exposed to various concentrations of the $\mathrm{T} 7$ peptide for $24 \mathrm{~h}$ and cell viability was determined using the CCK- 8 assay. As demonstrated in Fig. 1B, the viability of the HCC cells exposed to the T7 peptide was significantly decreased compared with the control cells, and the T7 peptide cytotoxicity increased in a concentration and time-dependent manner. T7 peptide at a concentration of $1 \mathrm{mM}$ induced the highest inhibitory rates for the two HCC cell lines; therefore, this concentration was selected for subsequent experiments. In contrast to malignant cells, the T7 peptide had little effect on the viability of L-02 cells (Fig. 1C).

Treatment with the T7 peptide induces apoptosis and cell cycle arrest in human HCC cells. Our previous study reported that the T7 peptide can induce apoptosis in HUVECs. Therefore, in the present study, apoptosis of HCC cells was analyzed by flow cytometry following PI and Annexin V-FITC staining. As presented in Fig. 2A and B, treatment with the T7 peptide significantly enhanced apoptotic cell death in Huh-7 and Hep3B cells. Next, the effects of the T7 peptide on the cell cycle phase distribution of human HCC cells were investigated. As expected, Huh-7 and Hep3B cells were arrested in the G1 phase following $24 \mathrm{~h}$ treatment with the T7 peptide (Fig. 2C). These results suggested that treatment of HCC cells with the $\mathrm{T} 7$ peptide resulted in $\mathrm{G} 0 / \mathrm{G} 1$ arrest of the cell cycle.

Treatment with the T7 peptide promotes Bax and Fas/FasL expression and suppresses Bcl-2 expression in human HCC cells. The balance between pro-apoptotic and anti-apoptotic proteins of the Bcl-2 family, including Bax and Bcl-2, serves an important role in cell survival in the early phase of the apoptotic cascade. In our previous study, it was demonstrated that the $\mathrm{T} 7$ peptide can reduce expression of the anti-apoptotic protein Bcl-2 and reverse the decrease in expression of the pro-apoptotic protein Bax induced by hypoxia (12). In the present study, the effects of $\mathrm{T} 7$ peptide treatment on Bcl-2 and Bax protein levels were investigated in Huh-7 and Hep3B cells. As presented in Fig. 3A, treatment of HCC cells with the $\mathrm{T} 7$ peptide resulted in downregulation of Bcl-2 and upregulation of Bax expression, in a concentration-dependent manner. Fas, a cell surface receptor protein, which induces apoptosis upon binding FasL, is the key regulator in the extrinsic pathway for apoptosis. Western blot analysis was used to explore the expression levels of the Fas and FasL proteins. As presented in Fig. 3A, the expression levels of Fas and FasL were markedly increased following treatment with the $\mathrm{T} 7$ peptide. These data revealed that $\mathrm{T} 7$ peptide-induced apoptotic cell death might involve both intrinsic and extrinsic pathways.

Treatment with the T7 peptide induces autophagy in human HCC cells. Autophagy has a crucial role in coping with multiple forms of cellular stress, including hypoxia, reactive oxygen species and DNA damage (18-21). Our previous study revealed, through the acridine orange staining assay, that the T7 peptide can induce autophagosome formation in HUVECs (12). To further investigate the antitumor mechanism of T7 peptide in human HCC cells, the effects of the T7 peptide on autophagy target genes were detected. As presented in Fig. 3B, the T7 peptide markedly enhanced expression of 

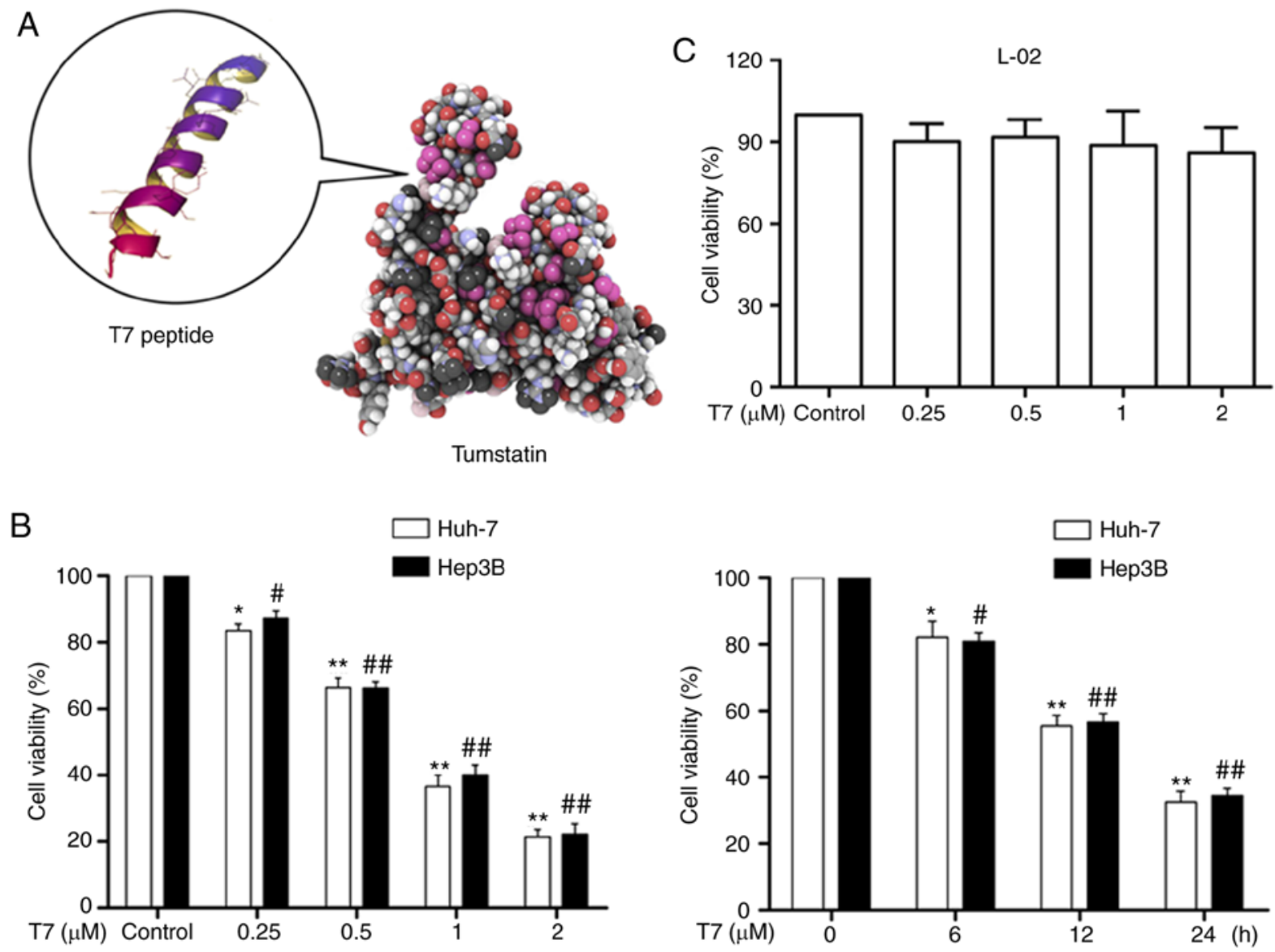

Figure 1. Treatment with the T7 peptide reduces cell viability of human hepatocellular carcinoma cells in vitro. (A) Schematic of the T7 peptide. (B) Huh-7 and Hep3B cells were treated with the T7 peptide at various concentrations $(0-2 \mu \mathrm{M})$ for $24 \mathrm{~h}$, or treated with $1 \mu \mathrm{M}$ T7 peptide for the indicated timepoints (1-24 h), and cell viability was determined by CCK-8 assay. (C) The normal human liver cell line, L-02, was incubated with the T7 peptide at various concentrations $(0-2 \mu \mathrm{M})$ for $24 \mathrm{~h}$, and the cell viability was determined by CCK- 8 assay. Data are expressed as the means \pm standard deviation from three independent experiments. ${ }^{\mathrm{P}}<0.05,{ }^{* *} \mathrm{P}<0.01$ vs. the Huh-7 control; ${ }^{\prime} \mathrm{P}<0.05,{ }^{\# \#} \mathrm{P}<0.01$ vs. the Hep3B control.

Beclin-1, Atg5, and LC3, which are the major key autophagy molecules, in a concentration-dependent manner. To further ascertain if autophagosome formation was increased in HCC cells following treatment with the T7 peptide, LC3 was visualized by immunofluorescent staining. As presented in Fig. 3C, immunofluorescent staining of LC3 was notably increased in HCC cells following T7 peptide treatment.

Inhibition of autophagy enhances $T 7$ peptide-induced cell death in human HCC cells. A large number of studies have indicated that autophagy may have protective effects in cancer therapy $(22,23)$. Our previous studies also demonstrated that inhibition of autophagy by 3-MA, a specific inhibitor of autophagy, can enhance the pro-apoptotic activity of the COX-2 inhibitor by upregulating the expression of Bax in HCC cells (24) and blocking of autophagy by 3-MA can potentiate the anti-angiogenic activity of the $\mathrm{T} 7$ peptide in HUVECs (12). To further explore the role that autophagy exerts in T7 peptide-induced apoptosis in human HCC cells, the apoptotic effect of the T7 peptide in combination with 3-MA was examined. Based on results from our previous study (12), the dose $5 \mathrm{nM}$ was selected for the 3-MA treatments. The present results demonstrated that combination treatment with $5 \mathrm{nM}$ 3-MA significantly inhibited T7 peptide-induced autophagy (Fig. 4A and B) and potenti- ated $\mathrm{T} 7$ peptide-induced Bax and Fas as well as expression of FasL in Huh-7 and Hep3B cells (Fig. 4C and D). Suppression of autophagy by 3-MA combination treatment significantly enhanced T7 peptide-induced apoptosis in human HCC cells (Fig. 4E). Bafilomycin A1, a specific inhibitor of the vacuolar type $\mathrm{H}(+)$-ATPase (V-ATPase), has been reported to inhibit the turnover of autophagosomes. To further investigate the defensive role of autophagy in T7 peptide-induced apoptosis, Huh-7 and Hep3B cells were co-treated with the T7 peptide and bafilomycin A1 (5 nM) for $24 \mathrm{~h}$. The results revealed that bafilomycin A1 also enhanced T7 peptide-induced apoptosis (Fig. 4F). The present data suggested that autophagy may have a protective role in mediating $\mathrm{T} 7$ peptide-induced apoptosis in human HCC cells.

Treatment with the $T 7$ peptide induces autophagy activation via the Akt/mTOR signaling pathway. A large number of studies have demonstrated that the Akt/mTOR signaling pathway has an important role in cell proliferation and autophagy $(25,26)$. In our previous study, it was demonstrated that the T7 peptide decreases Ang2 expression via inhibition of Akt phosphorylation (12). To further explore the molecular mechanisms of T7 peptide-induced autophagy in human HCC cells, the potential involvement of this signaling pathway was investigated. As presented in Fig. 5A, expression levels 
A

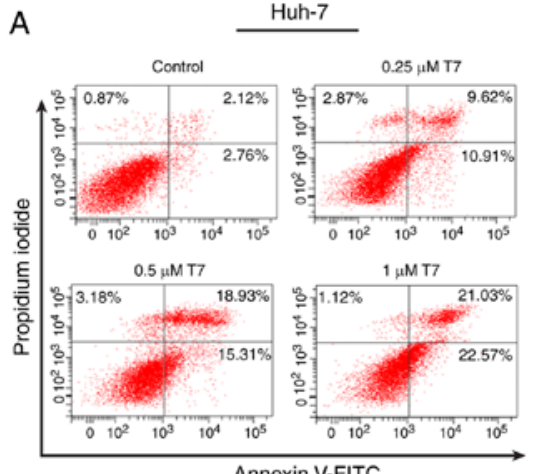

Annexin V-FITC

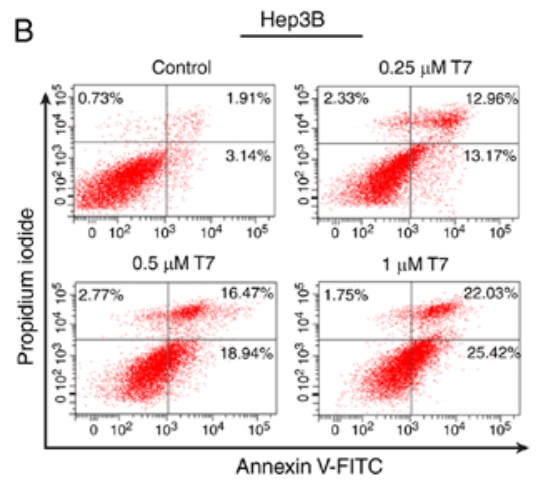

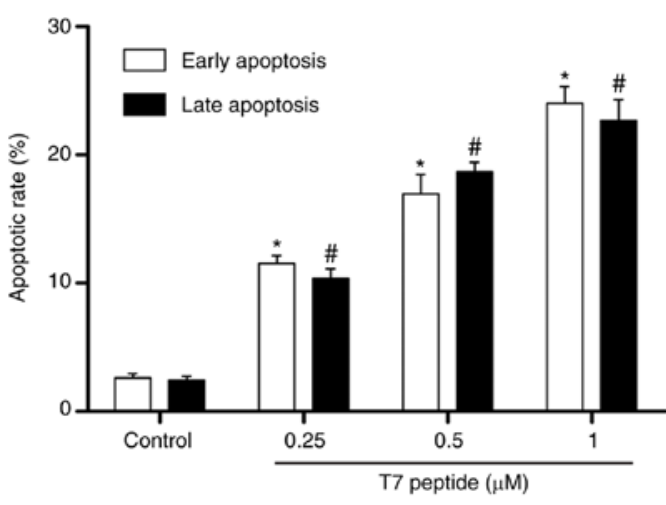

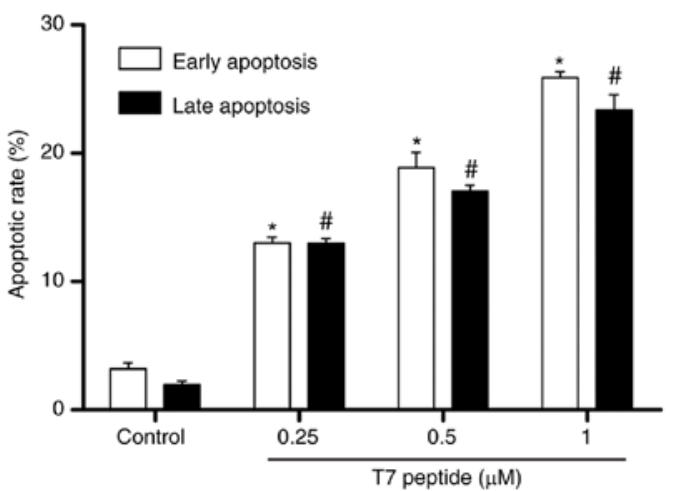

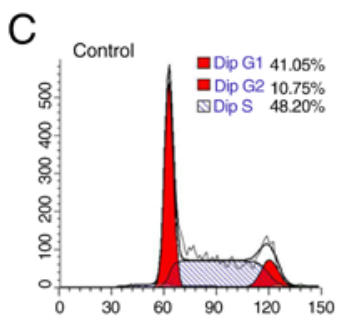
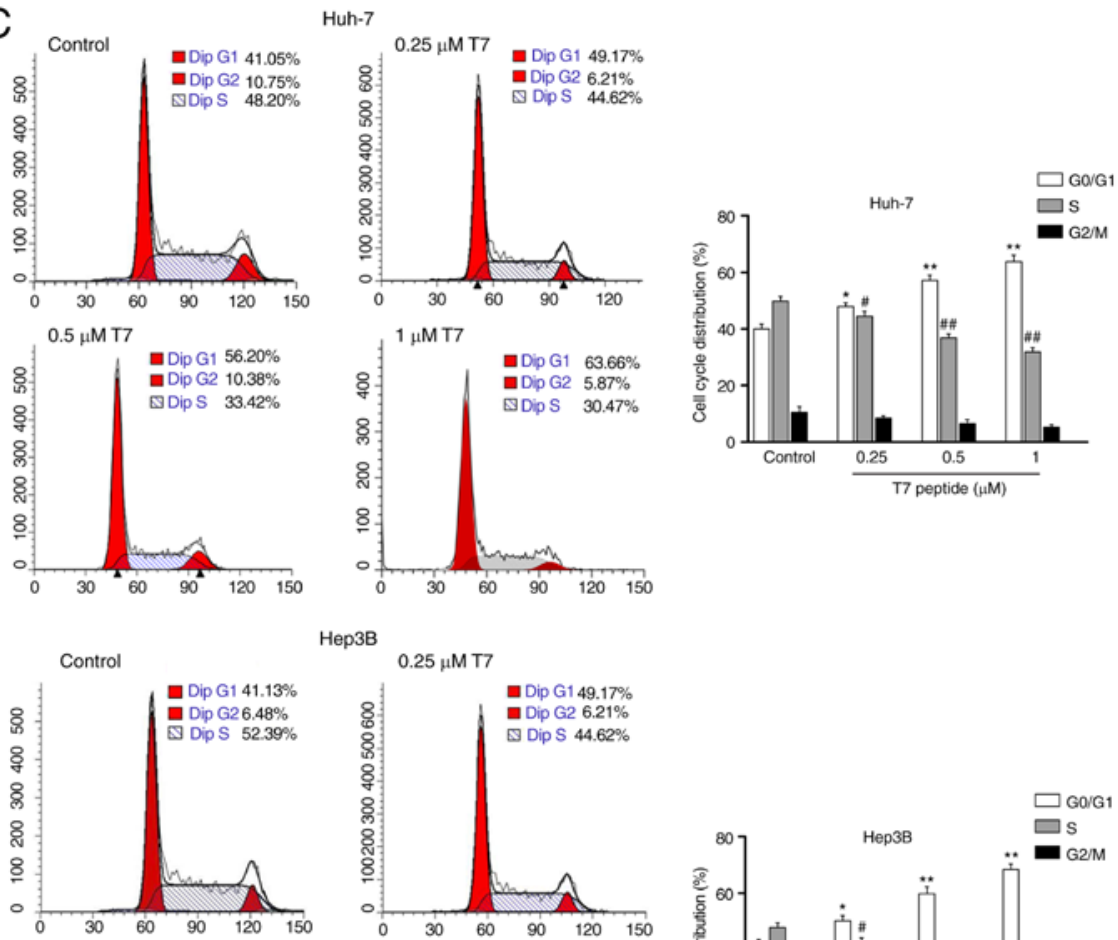

$0.25 \mu \mathrm{M} \mathrm{T7}$
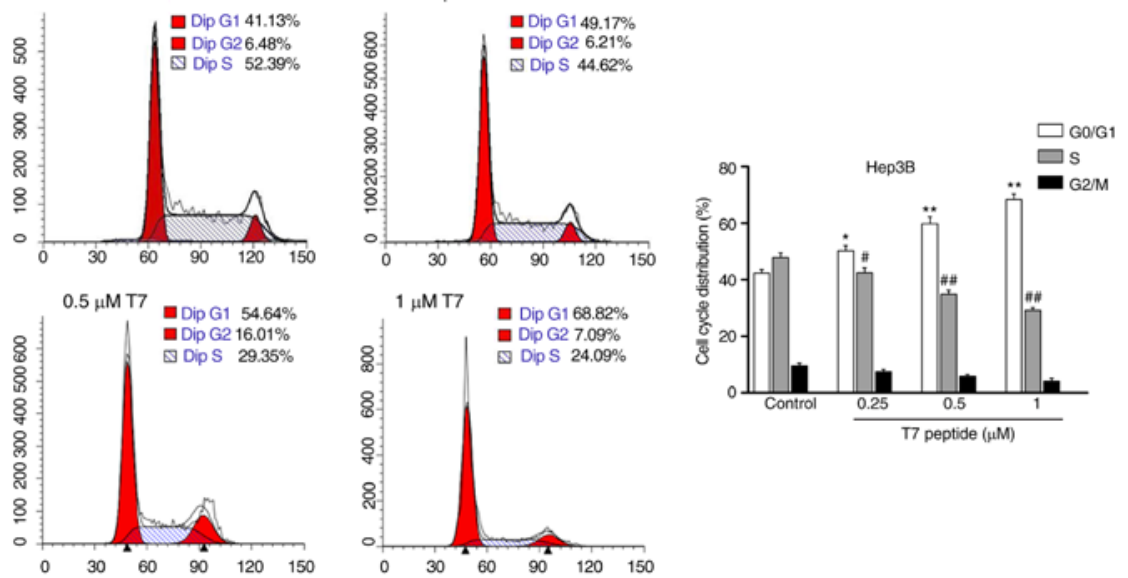

Figure 2. Treatment with the T7 peptide induces cell apoptosis and cell cycle arrest in human HCC cells in vitro. (A) Huh-7 and (B) Hep3B cells were treated with the T7 peptide $(0,0.25,0.5$ or $1 \mu \mathrm{M})$ for $24 \mathrm{~h}$. Apoptotic cells were analyzed by flow cytometry following PI and Annexin V-FITC staining. " $\mathrm{P}<0.01 \mathrm{vs}$. the control early apoptosis; ${ }^{~} \mathrm{P}<0.01$ vs. the control late apoptosis. (C) Cell cycle phase distribution of HCC cells was determined at $24 \mathrm{~h}$ following treatment with the T7 peptide. ${ }^{*} \mathrm{P}<0.05,{ }^{* *} \mathrm{P}<0.01$ vs. the control G0/G1 phase; ${ }^{\# /} \mathrm{P}<0.01$ vs. the control S phase. Data are presented as means \pm standard deviation from three independents experiments. HCC, hepatocellular carcinoma; PI, propidium iodide. 
A

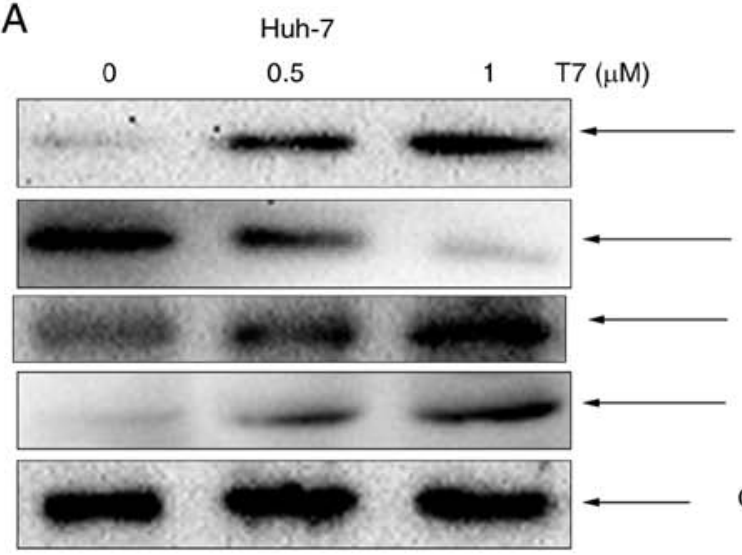

B

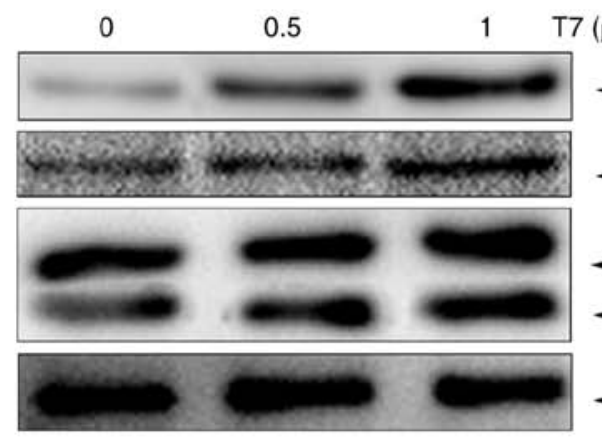

$\mathrm{T} 7(\mu \mathrm{M})$

C

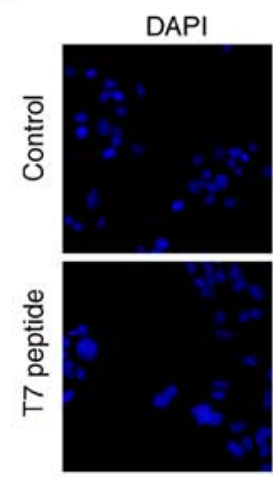

Huh-7
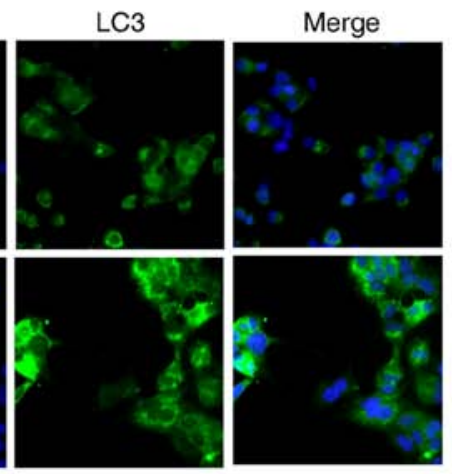

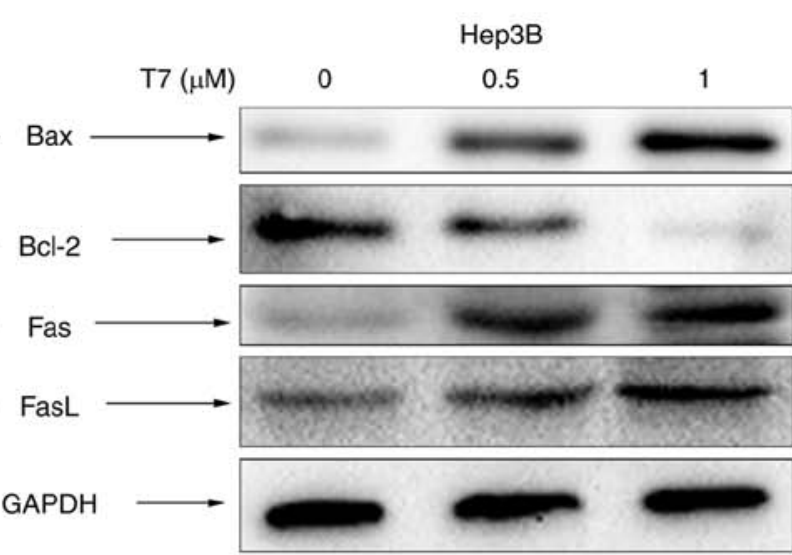

Hep3B
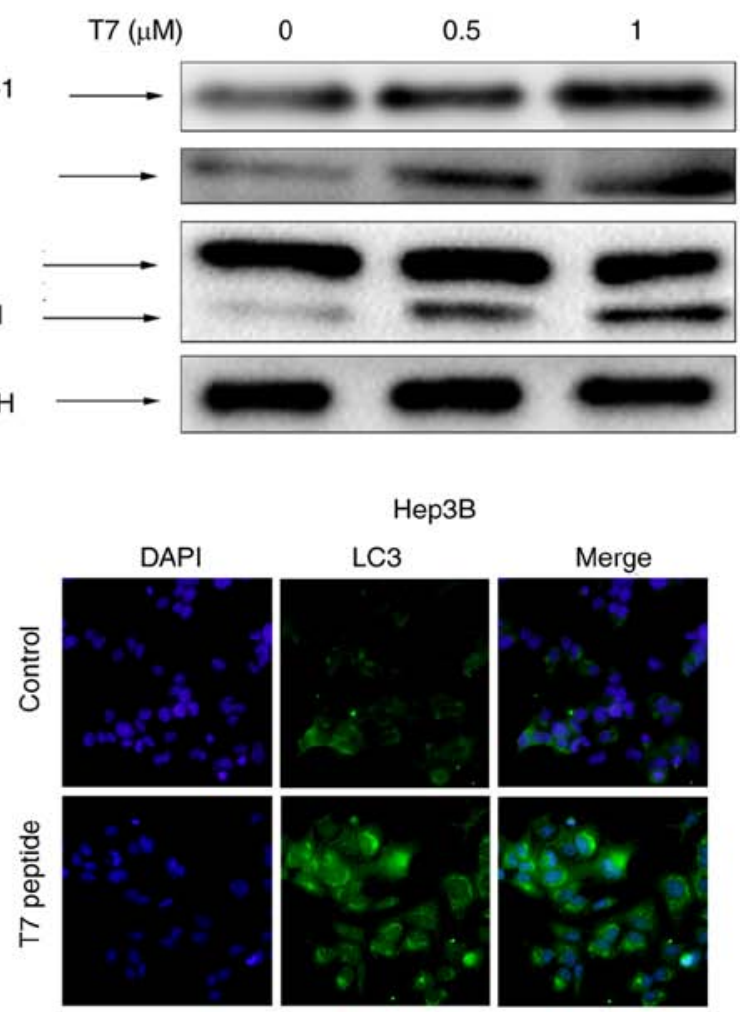

Figure 3. Treatment with the T7 peptide enhances Bax and Fas/FasL expression, alleviates Bcl-2 expression, and induces autophagy in human hepatocellular carcinoma cells in vitro. (A) Western blot analysis of Bax, Bcl-2, Fas and FasL protein expression levels. Representative blots from least three independent experiments. (B) Western blot analysis of autophagy-related molecules Beclin-1, Atg5, and LC3. Representative blots from least three independent experiments . GAPDH served as a loading control. (C) Immunofluorescent photomicrographs show expression of LC3 in Huh-7 and Hep3B cells (magnification, x200). FasL, Fas ligand; Atg5, autophagy-related 5; LC3, microtubule-associated protein 1 light chain $3 \alpha$.

of p-Akt (Ser473) and p-mTOR (Ser2448) in both Huh-7 and Hep3B cells were notably suppressed by the T7 peptide in a concentration-dependent manner. Next, the effects of the $\mathrm{T} 7$ peptide on this signaling pathway in the process of autophagy compared with MK-2206 (an Akt specific inhibitor) and rapamycin (an inhibitor of mTOR) were explored. The results demonstrated that both MK-2206 and rapamycin significantly potentiated T7 peptide-induced LC3 activation in HCC cells (Fig. 5B and D). Previous studies have revealed that insulin, not only activates the Akt/mTOR signaling pathway, but also inhibits autophagy $(27,28)$. As presented in Fig. 5C, insulin notably enhanced expression of p-Akt (Ser473) and p-mTOR (Ser2448). However, their phosphorylation levels were suppressed following pretreatment with the T7 peptide. In addition, the activation of LC3-II was notably inhibited by insulin in Huh-7 and Hep3B cells, whereas this effect of insulin was decreased by $\mathrm{T} 7$ peptide pretreatment (Fig. $5 \mathrm{C}$ and E). To further confirm the role of the Akt/mTOR pathway in HCC cells treated with the T7 peptide, the effect of MK-2206 and rapamycin on $\mathrm{T} 7$ peptide-induced apoptosis was evaluated. Flow cytometry analysis revealed that both MK-2206 and rapamycin could alleviate T7 peptide-induced HCC cell apoptosis (Fig. 5F), which was consistent with previous studies (29). The present results suggested that the T7 peptide induced autophagy in Huh-7 and Hep3B cells via blocking the $\mathrm{Akt} / \mathrm{mTOR}$ signaling pathway. 
A Huh-7
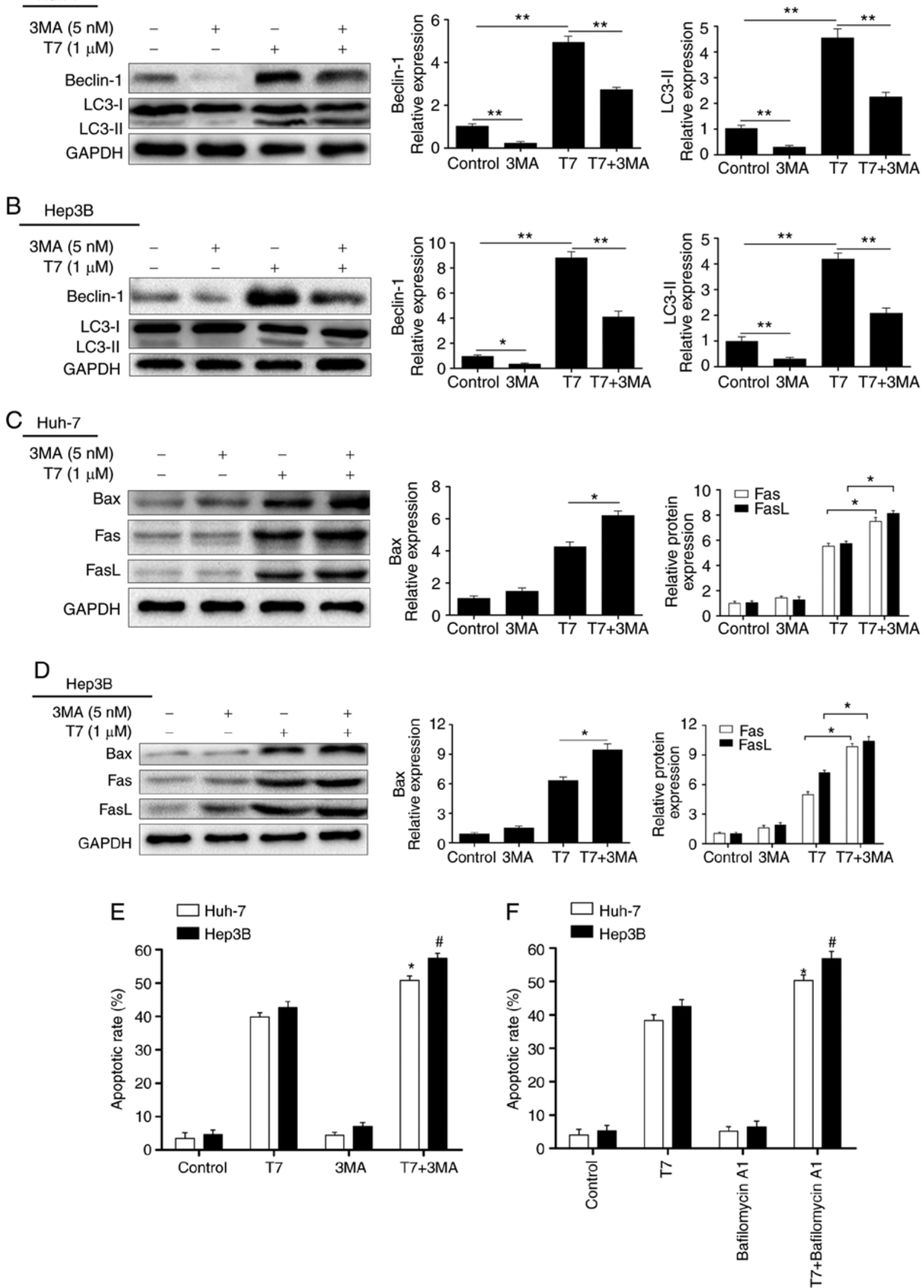

Figure 4. Inhibition of autophagy potentiates T7 peptide-induced apoptosis in human hepatocellular carcinoma cells in vitro. (A and B) Western blot analysis of autophagy-related molecules Beclin- 1 and LC3. GAPDH served as a loading control. " $\mathrm{P}<0.05$ and ${ }^{* *} \mathrm{P}<0.01$, with comparisons indicated by lines. (C and D) Western blot analysis of Bax, Fas and FasL. GAPDH served as a loading control. "P $<0.05$, with comparisons indicated by lines. (E and F) Apoptotic cells were analyzed by flow cytometry following propidium iodide and Annexin V-FITC staining. Quantitative analysis of the total apoptosis (early and late) population. Results are presented as means \pm standard deviation from at least three independent experiments. ${ }^{*} \mathrm{P}<0.05$ vs. T7-treated Huh-7; ${ }^{~} \mathrm{P}<0.05$ vs. T7-treated Hep3B. LC3, microtubule-associated protein 1 light chain 3 $\alpha$; FasL, Fas ligand. 

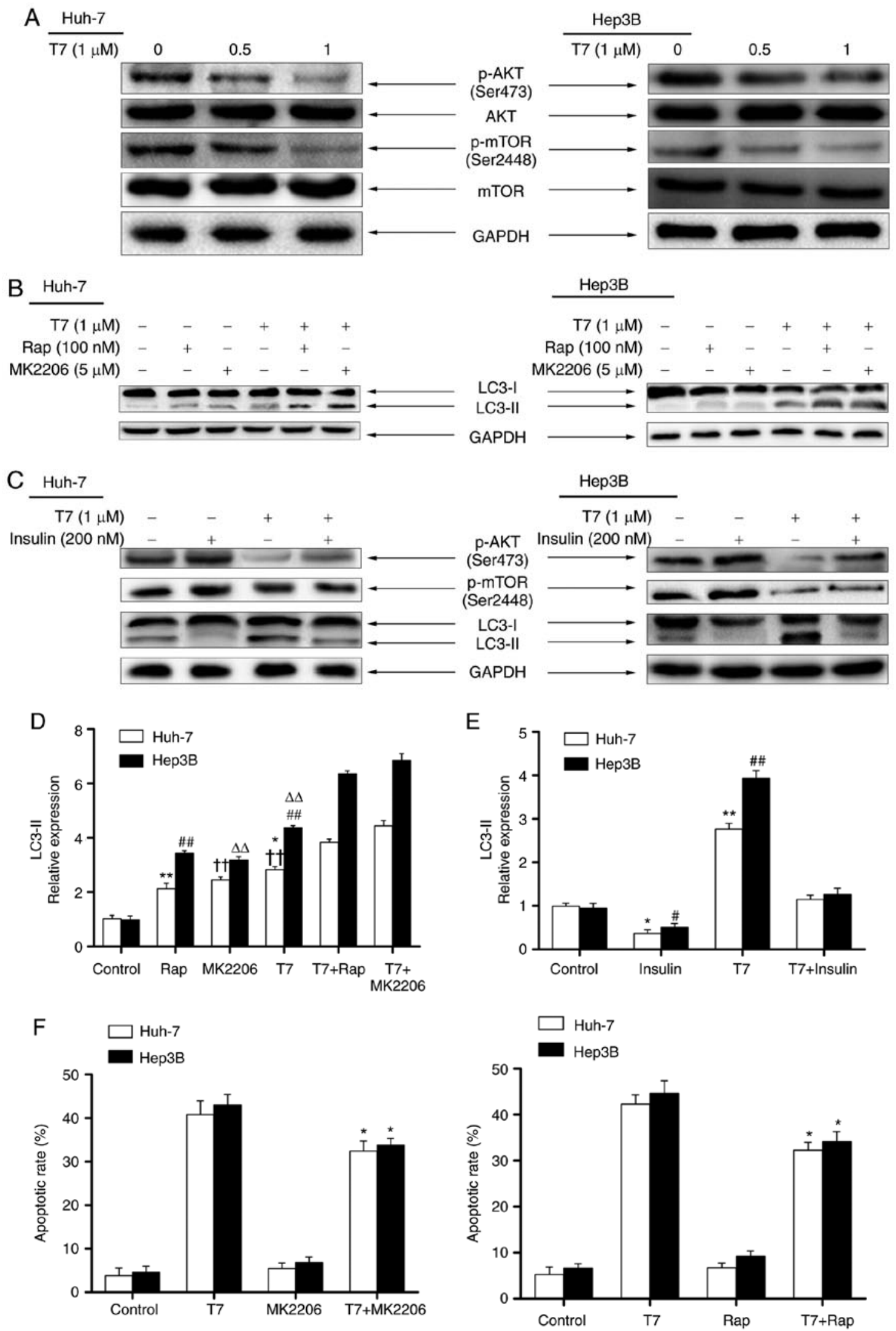

Figure 5. Effect of the T7 peptide on the Akt/mTOR signaling pathway in human hepatocellular carcinoma cells in vitro. (A) Cell lysates were harvested and analyzed by western blotting with specific antibodies against p-AKT (Ser473), AKT, p-mTOR (Ser2448) and mTOR. (B) Huh-7 and Hep3B cells treated with $1 \mu \mathrm{M}$ T7 peptide, $5 \mu \mathrm{M}$ MK-2206 or $100 \mathrm{nM}$ rapamycin for $24 \mathrm{~h}$ were analyzed by western blotting with antibodies against LC3. (C) Cells treated with $1 \mu \mathrm{M} \mathrm{T7}$ peptide for $24 \mathrm{~h}$, followed by treatment with or without $200 \mathrm{nM}$ insulin for $30 \mathrm{~min}$ were analyzed by western blotting for expression levels of p-AKT (Ser473), p-mTOR (Ser2448) and LC3. (D) Densitometric analysis of the LC3-II levels relative to GAPDH from panel B. ${ }^{*} \mathrm{P}<0.05$ and ${ }^{* *} \mathrm{P}<0.01$ vs. T7+Rap Huh-7 cells; ${ }^{* \#} \mathrm{P}<0.01$ vs. T7+Rap Hep3B cells; ${ }^{\dagger} \mathrm{P}<0.01$ vs. T7+ MK2206 Huh-7 cells; ${ }^{\Delta \Delta} \mathrm{P}<0.01$ vs. T7+ MK2206 Hep3B cells. (E) Densitometric analysis of the LC3- II levels from panel C. ${ }^{*} \mathrm{P}<0.05$ and ${ }^{* *} \mathrm{P}<0.01$ vs. T7+insulin Huh-7 cells; ${ }^{*} \mathrm{P}<0.05$ and ${ }^{\# \#} \mathrm{P}<0.01$ vs. T7+insulin Hep3B cells. (F) Apoptotic cells were analyzed by flow cytometry with propidium iodide and Annexin V-FITC staining. Quantitative analysis of total apoptosis (early and late) population is presented as means \pm standard deviation from at least three independent repeats. ${ }^{*} \mathrm{P}<0.05$ vs. T7 alone. p-, phosphorylated; LC3, microtubule-associated protein 1 light chain $3 \alpha$; Rap, rapamycin. 

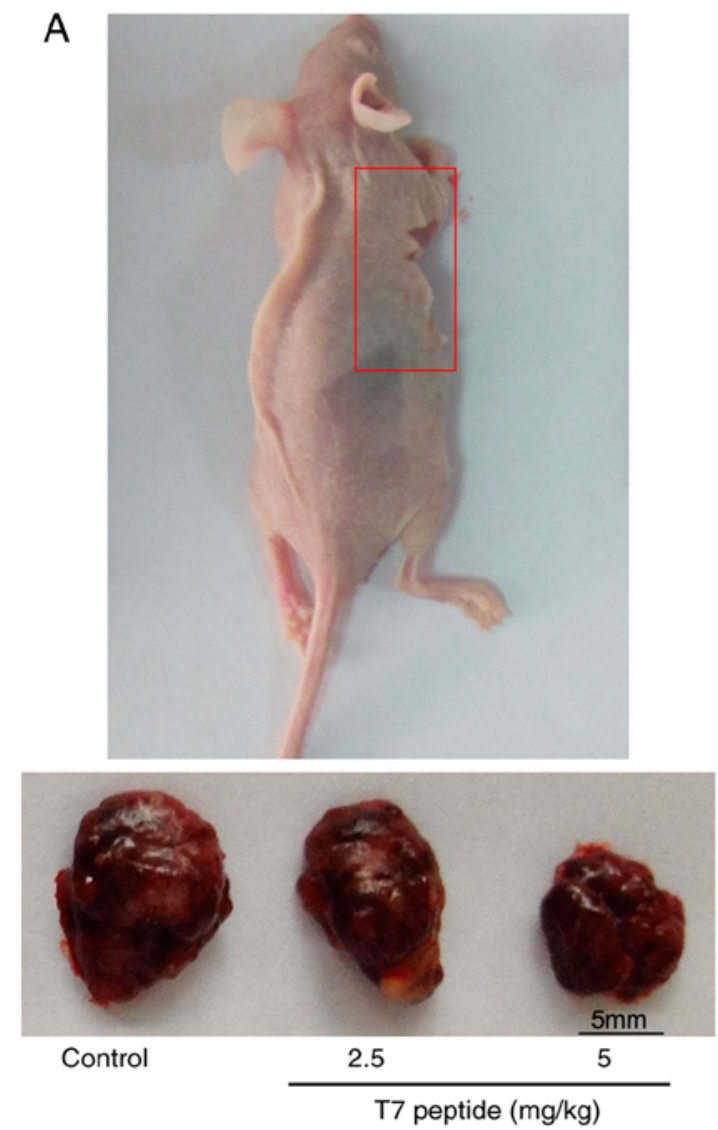

C

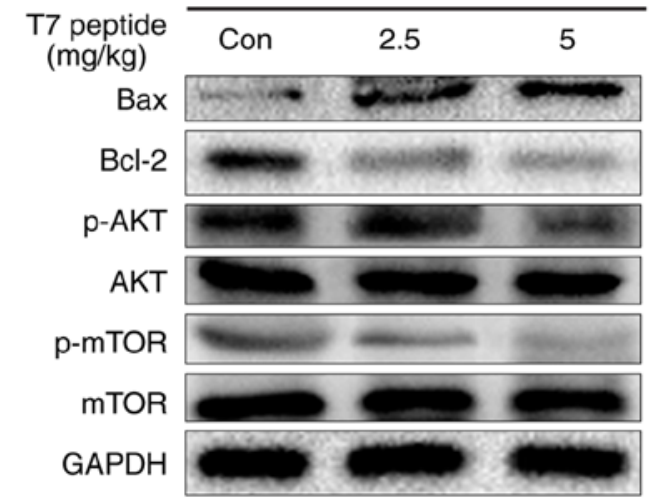

B
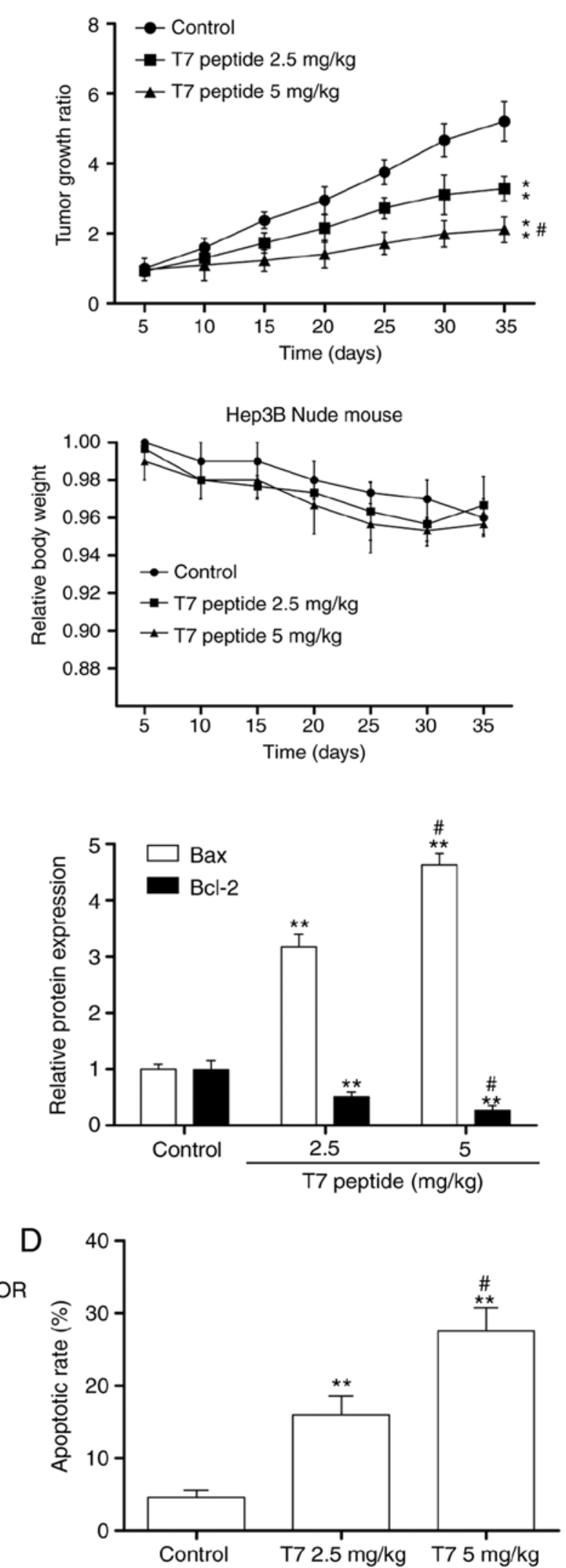

Figure 6. Treatment with the T7 peptide suppresses tumor growth in vivo. (A) Hep3B tumors were established in mice, and then injected with saline or different doses of the T7 peptide. The location of the tumors obtained from mice at the end of the experiments is shown in the red rectangle in the top panel. Representative images of tumors from each treatment group are shown in the lower panel. (B) The tumor size/weight was calculated throughout the duration of the experiment. Mouse body weight was also measured. ${ }^{* * *} \mathrm{P}<0.01$ vs. the saline-treated controls; ${ }^{\#} \mathrm{P}<0.05 \mathrm{vs}$. the T7 peptide $(2.5 \mathrm{mg} / \mathrm{kg})$. (C) Western blot analysis of Hep3B cell-derived tumors treated with the T7 peptide or saline control for expression of Bax, Bcl-2, p-AKT (Ser473), AKT, p-mTOR (Ser2448) and mTOR. GAPDH was used as the loading control. (D) Apoptosis was measured in the Hep3B tumor xenografts by TUNEL assay in vivo. Data are presented as the mean \pm standard deviation. ${ }^{* *} \mathrm{P}<0.01$ vs. the saline-treated controls; ${ }^{~} \mathrm{P}<0.05$ vs. the $\mathrm{T} 7$ peptide $(2.5 \mathrm{mg} / \mathrm{kg})$. $\mathrm{p}-$, phosphorylated. 
Treatment with the T7 peptide arrests tumor growth in vivo. Given the antitumor activity of the $\mathrm{T} 7$ peptide in vitro, the hypothesis that it may suppress HCC tumor growth in vivo was next investigated in a xenograft mouse model. As presented in Fig. 6A and B, treatment of the tumor-bearing mice with the T7 peptide notably suppressed the growth of Hep3B xenograft tumors. However, T7 peptide treatment did not cause obvious weight loss in the mice. Western blot analysis revealed that Bax expression increased and $\mathrm{Bcl}-2$ expression decreased in T7 peptide-treated Hep3B xenograft tumors. In addition, the levels of p-Akt and p-mTOR proteins significantly declined, whereas there were no significant differences in Akt and mTOR total protein expression in $\mathrm{T} 7$ peptide-treated groups compared with the control (Fig. 6C). To further investigate the inhibition of tumor growth caused by the T7 peptide, the apoptosis rates in the tumor tissues were analyzed by TUNEL assay. As presented in Fig. 6D, T7 peptide treatment resulted in a significant increase in TUNEL-positive tumor cells compared with the control group. Collectively, these data suggested that treatment with the $\mathrm{T} 7$ peptide reduced tumor growth in vivo.

\section{Discussion}

The T7 peptide, the 74-98 amino acid fragment of tumstatin, is an endogenous growth inhibitor that directly acts on tumor cells. Because of its small molecular weight, it is able to penetrate the tumor cells easily, with low immunogenicity and more stability, therefore it is expected to become valuable in tumor-specific diagnosis and cell-targeted treatment (12). However, the T7 peptide includes more hydrophobic amino acids, resulting in low solubility. Compared with traditional radiotherapy, chemotherapy and surgical treatment, tumstatin has strong anti-angiogenic effects as well as antitumor effects $(30,31)$. Research reports have demonstrated that tumstatin is active against various types of cancer $(32,33)$, but its extraction and purification is difficult due to its large molecular weight. In addition, as the autoantigen of lung-renal hemorrhagic syndrome, it may cause certain damage to kidney, lungs and other organs of the body and induce allergic reactions and other side effects, thus leading to safety concerns and limited clinical application (9). At present, a variety of active small peptides obtained on the basis of structural modification of tumstatin not only reduce the molecular weight but also retain the antitumor activity, improving its overall function and cancer targeting $(5,11)$. These active peptides have multiple advantages, including small molecular weight, safe use, easy extraction and purification, less cytotoxic side effects, high specificity, low risk of drug resistance, and high antitumor spectrum. They exhibit efficacy for most vascular-dependent solid tumors without effect on angiogenesis in physiological processes and are safe for clinical treatment $(30,34,35)$. Our previous study revealed that the $\mathrm{T} 7$ peptide inhibits angiogenesis in HUVECs via downregulation of Ang2 and autophagy (12). However, the detailed antitumor mechanism of the T7 peptide in HCC cells remained unknown. In the present study, it was demonstrated that the $\mathrm{T} 7$ peptide enhanced apoptosis of HCC cells both in vitro and in vivo.

Autophagy is a fundamental cellular homeostatic process involved in the turnover of long-lived proteins and whole organelles through lysosomal degradation. It serves a crucial role in regulating intracellular materials for energy production under stress. Many antitumor agents have been reported to lead to autophagy. Autophagy has been considered to have a paradoxical role in the control of cell death and survival. Some agents, such as including phenethyl isothiocyanate, can trigger autophagic cell death to enhance chemotherapeutic efficacy (36). However, other antitumor agents, such as arginine deiminase, induce autophagy that alleviates apoptotic cell death (37). Our previous study demonstrated that meloxicam, a selective COX-2 inhibitor, induced autophagy. Inhibition of autophagy could enhance its proapoptotic activity in HCC cells $(17,24)$. In the current study, the results revealed that treatment with the $\mathrm{T} 7$ peptide induced autophagy in Huh-7 and Hep3B cells both in vitro and in vivo. 3-MA, a selective and potent autophagy inhibitor, can suppress the formation of autophagosomes. The present results demonstrated that combination treatment with 3-MA enhanced T7 peptide-induced apoptosis in HCC cells by inhibiting the level of Beclin-1 and LC3 proteins and by increasing expression of Bax, Fas and FasL. Furthermore, it was also observed that bafilomycin A1 increased T7 peptide-induced apoptotic cell death of Huh-7 and Hep3B cells, indicating that the formation of autophagosomes induced by the $\mathrm{T} 7$ peptide had a protective role in human HCC cells.

The Akt/mTOR signaling pathway has an important role in regulating cell growth, proliferation, survival and motility. In addition, it is considered a major negative signaling pathway against autophagy (38). Accumulating evidence has demonstrated that blocking Akt and its downstream target mTOR can contribute to the initiation of autophagy (39). In the present study, it was demonstrated that treatment with the T7 peptide inhibited the phosphorylation of Akt (Ser473) and mTOR (Ser2448) both in vitro and in vivo. In addition, expression of LC3-II was increased by T7 peptide co-treatment with MK-2206 (an Akt specific inhibitor) or rapamycin (an inhibitor of mTOR) compared with single agent treatment alone, which suggested that the $\mathrm{T} 7$ peptide had a synergistic role in inducing autophagy with MK-2206 or rapamycin. Subsequently, insulin was employed to further investigate the correlation between insulin-induced activation of the Akt/mTOR signaling pathway and T7 peptide-induced autophagy. The present results revealed that insulin significantly enhanced expression of p-Akt (Ser473) and p-mTOR (Ser2448) and alleviated the activation of LC3-II, whereas these effects were weakened following co-treatment with the $\mathrm{T} 7$ peptide. The present data demonstrated that the Akt/mTOR pathway was involved in the T7 peptide-induced autophagy in Huh-7 and Hep3B cells.

In conclusion, the present study demonstrated that the T7 peptide inhibited the cell viability and induced autophagy in human HCC cells. Furthermore, the current data provided the first evidence that the T7 peptide resulted in autophagy through blocking the Akt/mTOR signaling pathway. Autophagy inhibitors potentiated the cytotoxic efficacy of the T7 peptide in human HCC cells. Therefore, it can be speculated that the T7 peptide may serve as an alternative therapeutic agent in the treatment of HCC. However, the present study has several limitations, including using only one cell type, as well as not using the autophagy inhibitor in vivo. Future studies will investigate the mechanism underlying the T7 peptide-induced cytotoxic effect in HCC cells in vivo, especially in combination with autophagy inhibitors. 


\section{Acknowledgements}

Not applicable.

\section{Funding}

This research was supported by the National Natural Scientific Foundation of China (grant no. 81802458), and the Youth Startup Foundation of Shandong Cancer Hospital and the National Science Foundation of Shandong Province (grant no. ZR201702210502).

\section{Availability of data and materials}

All data generated or analyzed during this study are included in this published article.

\section{Authors' contributions}

JZ conceived and designed the study. FL, FW, XD and PX conducted the experiments and wrote the manuscript. PS and ZL analyzed the data. XS and JZ revised the manuscript. All the authors read and approved the final manuscript.

\section{Ethics approval and consent to participate}

Experimental protocols involving the use of animals were approved by the Committee of Animal Experimentation and the Ethics Committee of Qianfoshan Hospital, Shandong University.

\section{Patient consent for publication}

Not applicable.

\section{Competing interests}

The authors declare that they have no competing interests.

\section{References}

1. Siegel RL, Miller KD and Jemal A: Cancer statistics, 2017. CA Cancer J Clin 67: 7-30, 2017.

2. Bruix J, Gores GJ and Mazzaferro V: Hepatocellular carcinoma: Clinical frontiers and perspectives. Gut 63: 844-855, 2014.

3. Pan JH, Zhou H, Zhao XX, Ding H, Li W, Qin L and Pan YL: Role of exosomes and exosomal microRNAs in hepatocellular carcinoma: Potential in diagnosis and antitumour treatments (Review). Int J Mol Med 41: 1809-1816, 2018.

4. Burgess JK, Boustany S, Moir LM, Weckmann M, Lau JY, Grafton K, Baraket M, Hansbro PM, Hansbro NG, Foster PS, et al: Reduction of tumstatin in asthmatic airways contributes to angiogenesis, inflammation, and hyperresponsiveness. Am J Respir Crit Care Med 181: 106-115, 2010.

5. Liu Y,Li J,XuH,Zhang Y,Liu Y andLiu X:Mitochondria-mediated tumstatin peptide-induced HepG2 cell apoptosis. Int J Mol Med 24: 653-659, 2009.

6. Hwang-Bo J, Park JH and Chung IS: Tumstatin induces apoptosis mediated by Fas signaling pathway in oral squamous cell carcinoma SCC-VII cells. Oncol Lett 10: 1016-1022, 2015.

7. Zhang P, Zhou Q, Tian L, Zhou X, Zhou Y and Chen J: Experimental study of a novel tumstatin on C6 brain glioma in vitro. Oncol Lett 14: 2845-2851, 2017.

8. Yan Y, Xu W, Qian H, Zhu W, Mao F and Zhang X: Tumstatin45-132-TNFalpha suppresses tumour growth through anti-angiogenic effects and cytotoxicity. Biotechnol Appl Biochem 56: 119-127, 2010.
9. Saus J, Wieslander J, Langeveld JP, Quinones S and Hudson BG: Identification of the Goodpasture antigen as the alpha 3(IV) chain of collagen IV. J Biol Chem 263: 13374-13380, 1988.

10. Eikesdal HP, Sugimoto H, Birrane G, Maeshima Y, Cooke VG, Kieran $M$ and Kalluri R: Identification of amino acids essential for the antiangiogenic activity of tumstatin and its use in combination antitumor activity. Proc Natl Acad Sci USA 105: 15040-15045, 2008.

11. Zhang X, Qi DD, Zhang TT, Chen QX, Wang GZ, Sui GY, Hao XW, Sun S, Song X and Chen YL: Antitumor activity of adenoviral vector containing T42 and 4xT42 peptide gene through inducing apoptosis of tumor cells and suppressing angiogenesis. Mol Med Rep 11: 2083-2091, 2015.

12. Wang F, Dong X, Xiu P, Zhong J, Wei H, Xu Z, Li T, Liu F, Sun $\mathrm{X}$ and Li J: T7 peptide inhibits angiogenesis via downregulation of angiopoietin-2 and autophagy. Oncol Rep 33: 675-684, 2015.

13. Yang $Z$ and Klionsky DJ: Eaten alive: A history of macroautophagy. Nat Cell Biol 12: 814-822, 2010.

14. Liu W, Wang X, Liu Z, Wang Y, Yin B, Yu P, Duan X, Liao Z, Chen Y,Liu C, et al: SGK1 inhibition induces autophagy-dependent apoptosis via the mTOR-Foxo3a pathway. Br J Cancer 117: 1139-1153, 2017.

15. Tang ZH, Cao WX, Su MX, Chen X and Lu JJ: Osimertinib induces autophagy and apoptosis via reactive oxygen species generation in non-small cell lung cancer cells. Toxicol Appl Pharmacol 321: 18-26, 2017.

16. Sun K, Guo XL, Zhao QD, Jing YY, Kou XR, Xie XQ, Zhou Y, Cai N, Gao L, Zhao X, et al: Paradoxical role of autophagy in the dysplastic and tumor-forming stages of hepatocarcinoma development in rats. Cell Death Dis 4: e501, 2013.

17. Zhong J, Dong X, Xiu P, Wang F, Liu J, Wei H, Xu Z, Liu F, Li T and Li J: Blocking autophagy enhances meloxicam lethality to hepatocellular carcinoma by promotion of endoplasmic reticulum stress. Cell Prolif 48: 691-704, 2015.

18. Cosin-Roger J, Simmen S, Melhem H, Atrott K, Frey-Wagner I, Hausmann M, de Vallière $\mathrm{C}$, Spalinger MR, Spielmann $\mathrm{P}$, Wenger RH, et al: Hypoxia ameliorates intestinal inflammation through NLRP3/mTOR downregulation and autophagy activation. Nat Commun 8: 98, 2017.

19. Shi ZY, Deng JX, Fu S, Wang L, Wang Q, Liu B, Li YQ and Deng JB: Protective effect of autophagy in neural ischemia and hypoxia: Negative regulation of the Wnt/ $\beta$-catenin pathway. Int J Mol Med 40: 1699-1708, 2017.

20. Chen YF, Liu H, Luo XJ, Zhao Z, Zou ZY, Li J, Lin XJ and Liang Y: The roles of reactive oxygen species (ROS) and autophagy in the survival and death of leukemia cells. Crit Rev Oncol Hematol 112: 21-30, 2017.

21. Li R, Luo X, Zhu Y, Zhao L, Li L, Peng Q, Ma M and Gao Y: ATM signals to AMPK to promote autophagy and positively regulate DNA damage in response to cadmium-induced ROS in mouse spermatocytes. Environ Pollut 231: 1560-1568, 2017.

22. Yang C, Ma X, Wang Z, Zeng X, Hu Z, Ye Z and Shen G: Curcumin induces apoptosis and protective autophagy in castration-resistant prostate cancer cells through iron chelation. Drug Design Devel Ther 11: 431-439, 2017.

23. Zhang N, Wu Y, Lyu X, Li B, Yan X, Xiong H, Li X, Huang G, Zeng Y, Zhang Y, et al: HSF1 upregulates ATG4B expression and enhances epirubicin-induced protective autophagy in hepatocellular carcinoma cells. Cancer Lett 409: 81-90, 2017.

24. Dong X, Li R, Xiu P, Dong X, Xu Z, Zhai B, Liu F, Jiang H, Sun X, Li J and Qiao H: Meloxicam executes its antitumor effects against hepatocellular carcinoma in COX-2-dependent and -independent pathways. PLoS One 9: e92864, 2014.

25. Chang H, Li X, Cai Q, Li C, Tian L, Chen J, Xing X, Gan Y, Ouyang $\mathrm{W}$ and Yang Z: The PI3K/Akt/mTOR pathway is involved in CVB3-induced autophagy of HeLa cells. Int J Mol Med 40: 182-192, 2017.

26. Wang SS, Chen YH, Chen N, Wang LJ, Chen DX, Weng HL, Dooley S and Ding HG: Hydrogen sulfide promotes autophagy of hepatocellular carcinoma cells through the PI3K/Akt/mTOR signaling pathway. Cell Death Dis 8: e2688, 2017.

27. Yao $H$, Han $X$ and Han $X$ : The cardioprotection of the insulin-mediated PI3K/Akt/mTOR signaling pathway. Am J Cardiovasc Drugs 14: 433-442, 2014.

28. Zhao R, Chen M, Jiang Z, Zhao F, Xi B, Zhang X, Fu H and Zhou K: Platycodin-D induced autophagy in non-small cell lung cancer cells via PI3K/Akt/mTOR and MAPK signaling pathways. J Cancer 6: 623-631, 2015. 
29. Huang KH, Kuo KL, Ho IL, Chang HC, Chuang YT, Lin WC, Lee PY, Chang SC, Chiang CK, Pu YS, et al: Celecoxib-induced cytotoxic effect is potentiated by inhibition of autophagy in human urothelial carcinoma cells. PLoS One 8: e82034, 2013.

30. Goto T, Ishikawa H, Matsumoto K, Nishimura D, Kusaba M, Taura N, Shibata H, Miyaaki H, Ichikawa T, Hamasaki K, et al: Tum-1, a tumstatin fragment, gene delivery into hepatocellular carcinoma suppresses tumor growth through inhibiting angiogenesis. Int J Oncol 33: 33-40, 2008.

31. Li YJ, Sun LC, He Y, Liu XH, Liu M, Wang QM and Jin XM: The anti-tumor properties of two tumstatin peptide fragments in human gastric carcinoma. Acta Pharmacol Sin 30: 1307-1315, 2009.

32. Wang Y, Yin RF and Teng JS: Tumstatin induces apoptosis and stimulates phosphorylation of p65NF- $\kappa \mathrm{B}$ in human osteoblastic osteosarcoma Saos-2 cells. Oncol Rep 35: 3403-3408, 2016.

33. Sun C, He D, Ma C, Gao Z, Chen Y and Wang S: Bifunctional fusion proteins derived from tumstatin and 4-1BBL for targeted cancer therapy. Mol Pharm 16: 867-876, 2019.

34. Grafton KT, Moir LM, Black JL, Hansbro NG, Hansbro PM, Burgess JK and Oliver BG: LF-15 \& T7, synthetic peptides derived from tumstatin, attenuate aspects of airway remodelling in a murine model of chronic OVA-induced allergic airway disease. PLoS One 9: e85655, 2014.

35. He Y, Jiang Y, Li YJ, Liu XH, Zhang L, Liu LJ, Shi H, Li HN, Ma YC and Jin XM: 19-peptide, a fragment of tumstatin, inhibits the growth of poorly differentiated gastric carcinoma cells in vitro and in vivo. J Gastroenterol Hepatol 25: 935-941, 2010.
36. Bommareddy A, Hahm ER, Xiao D, Powolny AA, Fisher AL, Jiang Y and Singh SV: Atg5 regulates phenethyl isothiocyanate-induced autophagic and apoptotic cell death in human prostate cancer cells. Cancer Res 69: 3704-3712, 2009.

37. Kim RH, Coates JM, Bowles TL, McNerney GP, Sutcliffe J, Jung JU, Gandour-Edwards R, Chuang FY, Bold RJ and Kung HJ: Arginine deiminase as a novel therapy for prostate cancer induces autophagy and caspase-independent apoptosis. Cancer Res 69: 700-708, 2009.

38. Shintani T and Klionsky DJ: Autophagy in health and disease: A double-edged sword. Science 306: 990-995, 2004.

39. Xue JF, Shi ZM,Zou J and Li XL: Inhibition of PI3K/AKT/mTOR signaling pathway promotes autophagy of articular chondrocytes and attenuates inflammatory response in rats with osteoarthritis. Biomed Pharmacother 89: 1252-1261, 2017.

This work is licensed under a Creative Commons Attribution-NonCommercial-NoDerivatives 4.0 International (CC BY-NC-ND 4.0) License. 